\title{
O registro fossilífero de metazoários ediacaranos na América do Sul e suas implicações nos estudos sobre origem e complexificação da vida animal

\author{
Ediacaran metazoan fossil record from South America and its implications in the studies \\ about origin and complexification of animal life
}

\author{
Bruno Becker Kerber ${ }^{1}$, Ana Lucia Zucatti da Rosa², Sandra Garcia Gabas ${ }^{3}$, Juliana de Moraes Leme, \\ Mírian Liza Alves Forancelli Pacheco ${ }^{4}$ \\ 1'Departamento de Geologia Sedimentar e Ambiental, Instituto de Geociências, Universidade de São Paulo - USP, Rua do Lago 562, \\ CEP 05508-080, São Paulo, SP, BR (bruno.becker92@gmail.com; leme@usp.br; forancelli@gmail.com) \\ ${ }^{2}$ Centro de Pesquisa e Desenvolvimento Leopoldo Américo Miguêz de Mello, Superintendência de Pesquisa Exploração e \\ Produção, Rio de Janeiro, RJ, BR (azucatti@gmail.com) \\ ${ }^{3}$ Centro de Ciências Exatas e Tecnologia, Universidade Federal de Mato Grosso do Sul - UFMS, Campo Grande, MS, BR \\ (sandra.gabas@gmail.com) \\ ${ }^{4}$ Departamento de Biologia, universidade Federal de São Carlos, UFSCAR, Sorocaba, SP, BR (forancelli@ufscar.br)
}

Recebido em 07 de dezembro de 2012; aceito em 24 de maio de 2013

\begin{abstract}
Resumo
O Período Ediacarano marca o aparecimento dos primeiros organismos macroscópicos complexos no registro fóssil. Evidências atuais indicam que a biota de Ediacara é composta tanto por animais quanto por grupos de protistas gigantes extintos, além de algas e outros organismos sem afinidades comprovadas com representantes modernos. Fósseis dessa biota foram documentados em pelo menos 40 localidades no mundo. Na América do Sul, fósseis de metazoários ediacaranos são encontrados no Brasil, Paraguai, Uruguai e Argentina. Na maioria dessas localidades, são encontrados fósseis do último momento evolutivo da biota ediacarana, capazes de realizar esqueletogênese, tais como Cloudina e Corumbella, correlatos a assembleia Nama. Essa novidade evolutiva surgiu, provavelmente, em resposta a pressões de predação e mudanças químicas nos oceanos. Recentemente, foram encontrados fósseis de organismos de corpo mole, típicos de outra assembleia ediacarana (White Sea), em Santa Catarina (Brasil). Essa ocorrência é de grande relevância, uma vez que representa a única descoberta na América do Sul que apresenta organismos dessa assembleia. Este trabalho tem por objetivo compilar as ocorrências da biota de Ediacara na América do Sul, bem como discutir a importância da inserção e dos estudos dessas ocorrências no cenário mundial no escopo de uma das mais importantes questões da Paleobiologia: a origem e a evolução dos animais na Terra.
\end{abstract}

Palavras-chave: Biota de Ediacara; Metazoários ediacaranos; Evolução dos metazoários; Ediacarano na América do Sul.

\begin{abstract}
The Ediacaran Period marks the first appearance of complex macroscopic organisms in the fossil record. Current evidence indicates that Ediacara biota is composed of animals, groups of extinct giant protists, algae and other organisms without proven affinities with modern groups. Fossils of this biota have been documented in at least 40 locations worldwide. In South America, ediacaran metazoan fossils are found in Brazil, Paraguay, Uruguay and Argentina. In most of these locations, are found fossils of the last moment of evolutionary ediacaran biota, capable of performing skeletogenesis, such as Cloudina and Corumbella, related to Nama assemblage. This evolutionary novelty arose probably in response to predation pressures and chemical changes in the oceans. Newly, fossils of soft-bodied organisms were found, typical of other ediacaran assembly (White Sea), in Santa Catarina (Brazil). This occurrence is of great importance since it represents the only discovery about its assemblage in South America. This work aims to compile the occurrences of the Ediacara biota in South America, as well as discussing the importance of inclusion and study these events on the world scene in the scope of one of the most important issues of Paleobiology: the origin and evolution animals on Earth.
\end{abstract}

Keywords: Ediacaran biota; Ediacaran metazoans; Evolution of metazoans; Ediacaran in South America. 


\section{INTRODUÇÃO}

Na década de 1940, nas colinas de Ediacara, sul da Austrália, Sprigg $(1947,1949)$ evidenciou um conjunto de organismos até então considerados invertebrados fósseis cambrianos. Esses organismos ficaram, então, conhecidos como "fauna de Ediacara".

Assim, por muito tempo, os estudos sobre os organismos de Ediacara os apontavam seguramente como metazoários e/ou ancestrais destes, tais como cnidários, vermes segmentados, artrópodes e equinodermos (e.g. Fedonkin, 1987; Glaessner, 1983, 1984). Contudo, a partir dos trabalhos de Buss e Seilacher (1994), Seilacher (1983, 1984, 1989, 1992, 1999, 2007), e Seilacher et al. (2003) esses fósseis foram caracterizados como compostos por outros grupos não necessariamente e nem sempre relacionados aos metazoários (cf. Seilacher, 2007), sem representantes modernos no fim do Neoproterozoico (Crimes, 1987, 1989; Jenkins, 1984). Desse modo, "biota de Ediacara" foi o termo mais recentemente cunhado e aceito para abarcar a composição taxonômica dos organismos megascópicos de corpo mole do Ediacarano, com (Seilacher, 2007) ou sem afinidade definida (Seilacher, 1989, 1992), além dos outros táxons, tais como metazoários e algas multicelulares, que também comporiam essa biota (Xiao et al., 2002; Xiao e Laflamme, 2009; Yuan et al., 2011).

Grande parte dos organismos ediacaranos de corpo mole foi atribuída a um reino monofilético: os Vendobionta (Seilacher, 1992). Outras interpretações sugeriram que os vendobiontes poderiam constituir um grupo irmão dos Metazoa bilaterais (e deveriam ser reconhecidos como um filo dos metazoários) ou seriam um grupo irmão dos Cnidaria (atribuídos a uma classe desse filo) (Buss e Seilacher, 1994). Mas estudos mais recentes consideram os vendobiontes um grupo (ordem ou subclasse) extinto de rizópodes gigantes que, juntamente com os Xenophyophora, dominaram as comunidades bentônicas no fim do Proterozoico (Seilacher et al., 2003; Seilacher, 2007). Mesmo assim, há contraposições à interpretação protista dos vendobiontes (Antcliffe et al., 2011).

De qualquer forma, os vendobiontes são morfologicamente definidos como "organismos acolchoados", caracterizados por corpos ocos, recobertos por cutícula orgânica flexível, suscetíveis às pressões hidrostática e tubulares. Sua morfologia encontrava-se organizada em estruturas fractais, como os rangeomorfos (e.g. Rangea e Charnia - Figuras 1, 2B e 2D - Seilacher, 1992; Seilacher et al., 2003; Xiao e Laflamme, 2009), ou seriais, como os ernietomorfos (e.g. Ernietta e Pteridinium - Figura 1 - Seilacher, 1992; Seilacher et al., 2003) (Narbonne, 2004; Seilacher, 2007; Laflamme et al., 2009; Seilacher, 2007; Xiao e Laflamme, 2009).
A última compilação de dados demonstrou que a biota de Ediacara apresenta registro em pelo menos 40 localidades no mundo (Narbonne, 1998; Fedonkin et al., 2007; Xiao e Laflamme, 2009), sendo temporalmente dividida em 4 assembleias fósseis bem definidas: Lantian, Avalon, White Sea e Nama (Waggoner, 2003; Xiao e Laflamme, 2009; Yuan et al., 2011; vide Fairchild et al., 2012 para revisão).

Além da biota peculiar, o final do Ediacarano foi marcado por bruscas mudanças geoquímicas na água, podem refletir eventos de anoxia em mares rasos (Narbonne, 2005; Kimura e Watanabe, 2001). Em seguida, o registro fóssil do Eocambriano apresenta maior diversidade de icnofósseis e, pela primeira vez, verticais (Crimes, 1987). Esses icnofósseis mostram que os organismos começaram a utilizar o substrato para proteção e/ou forrageamento e refletem um período de reestruturação ecológica que se estabeleceu no Eocambriano e foi denominado "Revolução Agronômica" (Seilacher e Pflüger, 1994) ou "Revolução do Substrato Cambriano" (Bottjer et al., 2000). Antes dessa revolução ecológica, os organismos osmotróficos viviam fixos ao substrato e os poucos táxons providos de motilidade (e.g. Kimberella) apenas pastavam sobre as esteiras microbianas (Bottjer et al., 2000).

Considerando que a esqueletogênese e as atividades na infauna sejam estratégias também atribuídas à pressão de predação e, uma vez que os animais capazes de sintetizar esqueletos e os exploradores de substrato surgiram quase que ao mesmo tempo no registro, há um forte argumento de que a predação também tenha se revelado um fator ativo na reestruturação dos ecossistemas (Dzik, 2007).

Assim, a complexidade das teias tróficas não aumentou significativamente apenas devido ao aparecimento das primeiras formas de vida animal (Conway Morris e Robinson, 1986) mas também devido às intrínsecas mudanças que eles causaram no ambiente e à coevolução predador/presa, refletida na aquisição independente de esqueletos de animais e exploração de novos hábitats, culminando na explosão cambriana (Stanley, 1973; Bengtson, 1994; Wood, 2011).

Diante do estabelecimento de ecossistemas ecologicamente mais favoráveis aos metazoários, no contexto das mudanças provocadas pela "Revolução Agronômica", é muito provável que os vendobiontes e os demais protistas gigantes do Ediacarano tenham sido extintos a priori por condições ambientais desfavoráveis e também por predação e/ou competição. Ainda é bem possível que, a partir de um contexto ecológico estruturado por metazoários, os protistas gigantes tenham evoluído no sistema de intraguildas dominados pelos metazoários, para clados de tamanho reduzido e em hábitats mais improváveis de ocorrer sobreposições de nicho (Seilacher, 2007).

A biota de Ediacara, sem dúvida, corresponde a um dos mais profundos eventos na evolução da biosfera terrestre: 

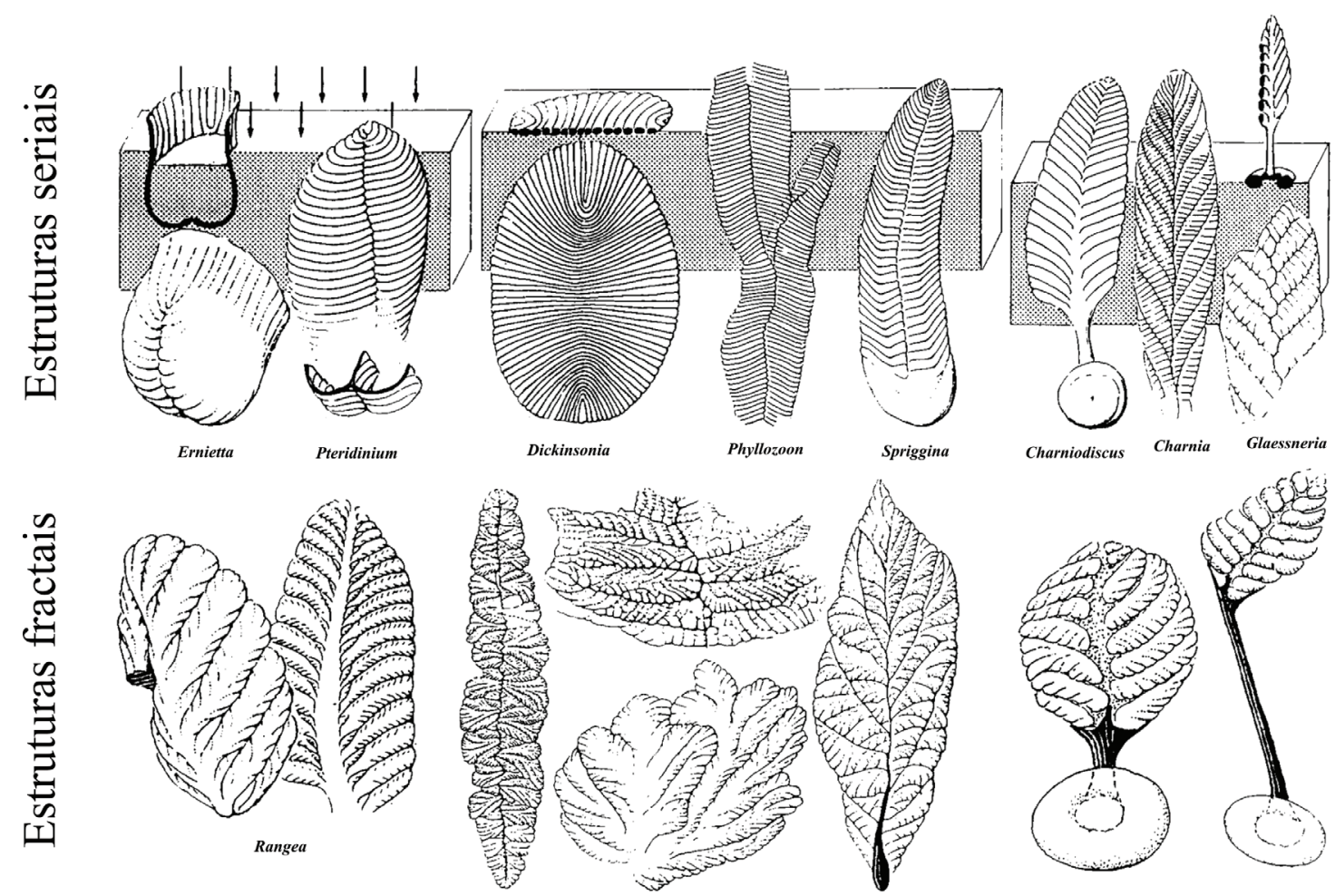

Aderidos ao sedimento

Em contato com o substrato pela maior área de superfície

Em contato com o substrato por região de fixação

Disposição vertical

Figura 1. Organização estrutural e modos de vida dos vendobiontes (modificado de Seilacher, 1992 e Seilacher et al., 2003).
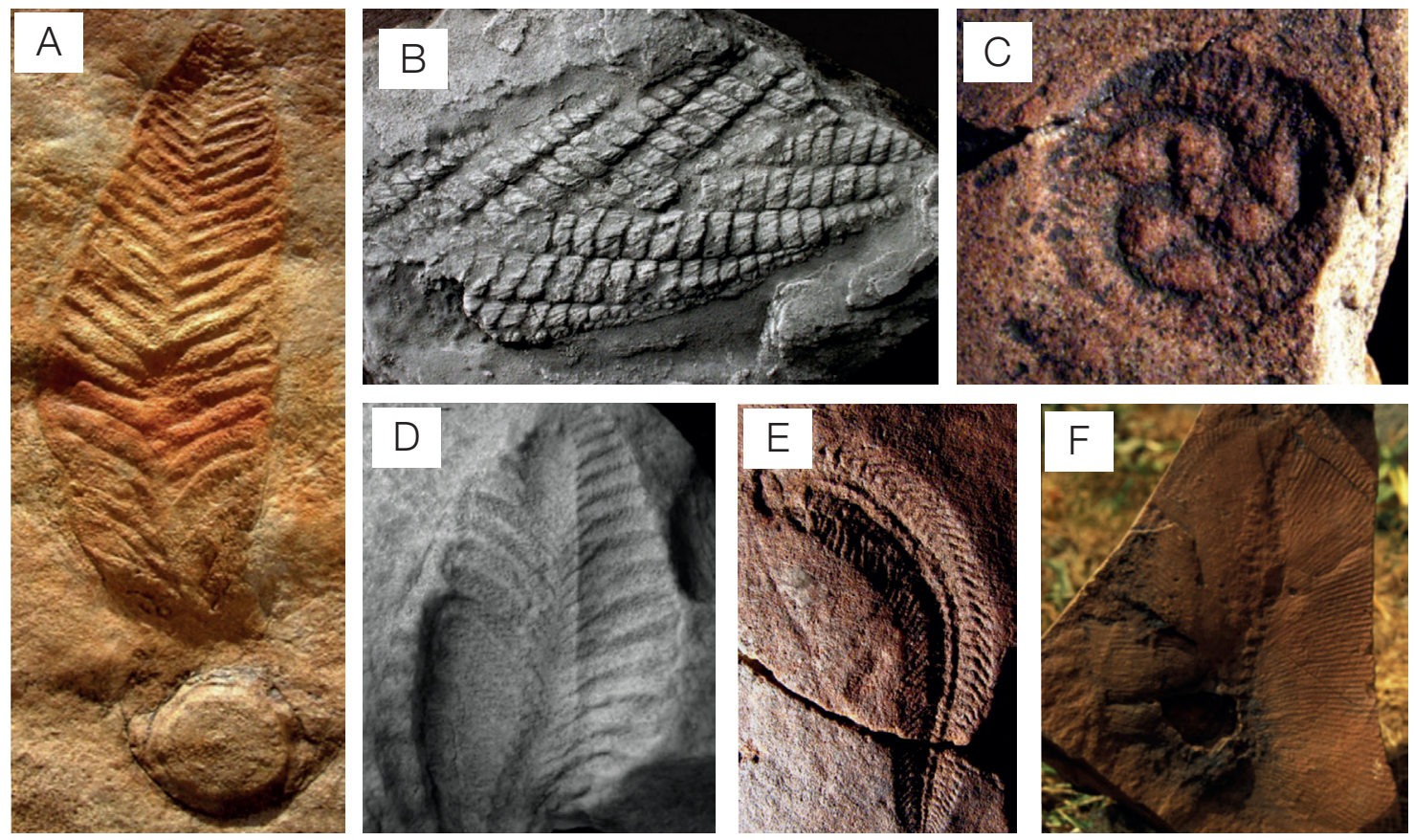

Figura 2. Planos corporais e morfologias da Biota de Ediacara. (A) Charniodiscus frondoso; (B) e (D) Charnia e Rangea fractais; (C) Tribrachidium, de simetria trirradial; (E) Spriggina, bilateral, com diferenciação ântero-posterior; (F) Swartpuntia frondoso. (modificado de Xiao e Laflamme, 2009). 
a emergência das formas de vida macroscópica evidenciada no registro fossilífero e o alvorecer da irradiação dos animais na Terra. Portanto, este trabalho tem por objetivo compilar as ocorrências da biota de Ediacara na América do Sul, bem como discutir a importância da inserção e dos estudos dessas ocorrências no cenário mundial no escopo de uma das mais importantes questões da Paleobiologia: a origem e a evolução dos animais na Terra.

\section{A BIOTA EDIACARANA NA AMÉRICA DO SUL}

Na América do Sul, restos de metazoários ediacaranos são encontrados no Brasil, Paraguai, Uruguai e
Argentina. Na maioria dessas localidades, são encontrados fósseis do último momento evolutivo da biota de Ediacara, dominado por metazoários capazes de realizar esqueletogênese, tais como Cloudina (Zaine e Fairchild, 1987; Meira, 2011) e Corumbella (Pacheco et al., 2011c; Warren et al., 2012). Recentemente, foram encontrados fósseis de organismos de corpo mole, típicos de outra assembleia ediacarana (White Sea), na Bacia do Itajaí, em Santa Catarina (Brasil) (Zucatti da Rosa, 2005). Todas as ocorrências de metazoários ediacaranos encontradas na América do Sul estão ilustradas no mapa da Figura 3, e as Tabelas 1 e 2 mostram todos os trabalhos realizados nessas localidades.

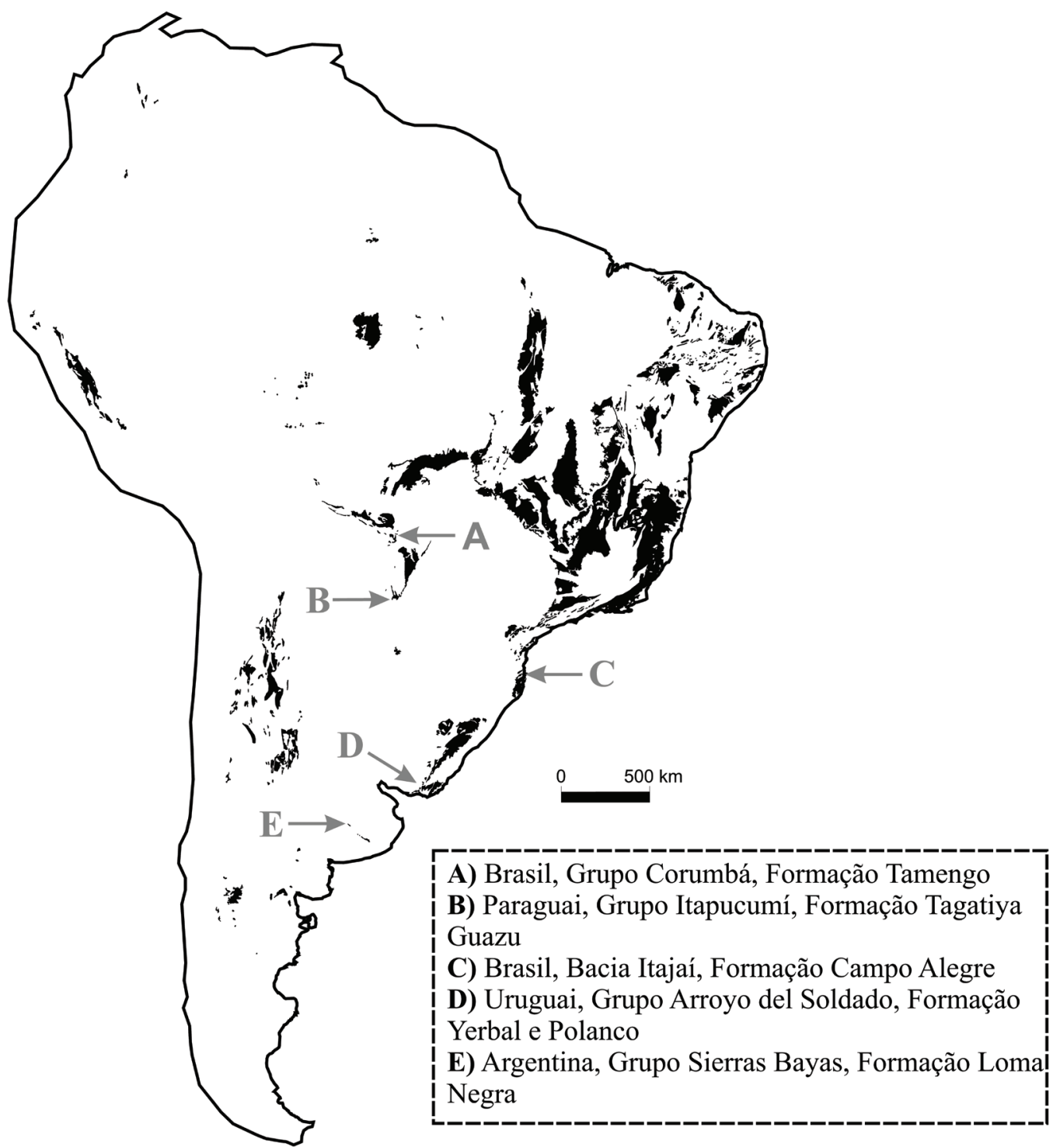

Figura 3. Distribuição dos fósseis ediacaranos no mapa da América do Sul. Em preto: rochas sedimentares neoproterozoicas. 


\section{Fósseis e estado da arte das pesquisas}

Cloudina (Germs, 1972)

Cloudina (Figura 4) consiste de conchas calcárias cônico-tubulares retilíneas ou, às vezes, encurvadas. São fechadas em uma das extremidades (proximal) e abertas na outra (distal).
Cada concha consiste de estruturas denominadas "funil-emfunil" (Figura 4), devido a forma como os funis se encaixam. Em seção transversal, as estruturas apresentam formas concêntricas que variam de circulares a ovaladas. A superfície externa é lisa ou irregular e a interna, lisa. Alguns espécimes apresentam pedúnculo basal ou espinhos (Hahn e Pflug, 1985; Zaine e Fairchild, 1987; Gaucher et al., 2003).

Tabela 1. Trabalhos realizados com fósseis de metazoários ediacaranos na América do Sul.

\begin{tabular}{|c|c|c|c|c|c|}
\hline Referência & $\begin{array}{l}\text { Unidade } \\
\text { geológica }\end{array}$ & Fóssil(eis) & Tipo de estudo & $\begin{array}{l}\text { Tipo de } \\
\text { trabalho }\end{array}$ & $\begin{array}{l}\text { Métodos aplicados à } \\
\text { análise dos fósseis }\end{array}$ \\
\hline Pacheco (2012) & 1 & Corumbella werneri & $\begin{array}{l}\text { Reconstituição morfológica e } \\
\text { afinidades filogenéticas }\end{array}$ & Tese & $\begin{array}{c}\text { Raman, Fluorescência } \\
\text { de Raios-X (XRF), } \\
\text { Microtomografia de } \\
\text { Raios-X }\end{array}$ \\
\hline $\begin{array}{l}\text { Fairchild } \\
\text { et al. (2012) }\end{array}$ & 1 e 3 & $\begin{array}{c}\text { C. werneri; } \\
\text { C. lucianoi; Choia; } \\
\text { Chancelloria; } \\
\text { discos; } \\
\text { Parvancorina }\end{array}$ & Revisão & Artigo & $\begin{array}{c}\text { Revisão e perspectivas, } \\
\text { sem aplicações de } \\
\text { métodos }\end{array}$ \\
\hline $\begin{array}{l}\text { Warren } \\
\text { et al. (2012) }\end{array}$ & 4 & Corumbella werneri & Análise de ultraestrutura & Artigo & $\begin{array}{l}\text { Microscopia eletrônica } \\
\text { de varredura (MEV) } \\
\text { e Microanálise semi- } \\
\text { quantitativa (EDS) }\end{array}$ \\
\hline $\begin{array}{l}\text { Warren } \\
\text { et al. (2011) }\end{array}$ & 4 & $\begin{array}{l}\text { Corumbella werneri; } \\
\text { Cloudina lucianoi }\end{array}$ & $\begin{array}{c}\text { Classificação taxonômica, } \\
\text { tafonomia, paleoambiente e } \\
\text { paleogeografia }\end{array}$ & Artigo & $\begin{array}{c}\text { Análises paleontológicas } \\
\text { clássicas }\end{array}$ \\
\hline $\begin{array}{l}\text { Pacheco } \\
\text { et al. (2011c) }\end{array}$ & 1 & Corumbella werneri & $\begin{array}{c}\text { Tafonomia e reconstituição da } \\
\text { morfologia original }\end{array}$ & Artigo & Modelagem geométrica \\
\hline $\begin{array}{l}\text { Pacheco } \\
\text { et al. (2011c) }\end{array}$ & & Corumbella werneri & $\begin{array}{c}\text { Análise de composição } \\
\text { química }\end{array}$ & $\begin{array}{l}\text { Relatório de } \\
\text { atividade }\end{array}$ & $\begin{array}{l}\text { Fluorescência de } \\
\text { Raios-X (XRF) }\end{array}$ \\
\hline $\begin{array}{l}\text { Pacheco } \\
\text { et al. (2011b) }\end{array}$ & 1 & Corumbella werneri & $\begin{array}{l}\text { Tafonomia e afinidades } \\
\text { filogenéticas }\end{array}$ & $\begin{array}{l}\text { Resumo } \\
\text { expandido }\end{array}$ & Estereomicroscopia \\
\hline $\begin{array}{l}\text { Pacheco e } \\
\text { Leme (2011) }\end{array}$ & 1 & Corumbella werneri & $\begin{array}{c}\text { Utilização de técnicas } \\
\text { modernas para estudo do } \\
\text { fóssil }\end{array}$ & Resumo & Espectroscopia Raman \\
\hline Meira (2011) & 1 e 2 & Cloudina lucianoi & $\begin{array}{c}\text { Classificação taxonômica, } \\
\text { bioestratigrafia, tafonomia } \\
\text { e interpretações } \\
\text { paleoambientais }\end{array}$ & Dissertação & $\begin{array}{l}\text { Estereomicroscopia, } \\
\text { Microscópio Eletrônico } \\
\text { de Varredura (MEV) }\end{array}$ \\
\hline $\begin{array}{l}\text { Pacheco } \\
\text { et al. (2010a) }\end{array}$ & 1 & Corumbella werneri & $\begin{array}{l}\text { Tafonomia e afinidades } \\
\text { filogenéticas }\end{array}$ & Resumo & Estereomicroscopia \\
\hline $\begin{array}{l}\text { Pacheco } \\
\text { et al. (2010b) }\end{array}$ & 1 & Corumbella werneri & $\begin{array}{c}\text { Morfologia e suas implicações } \\
\text { filogenéticas }\end{array}$ & Resumo & Estereomicroscopia \\
\hline $\begin{array}{l}\text { Zucatti Da Rosa } \\
\text { (2005) }\end{array}$ & 3 & $\begin{array}{c}\text { Chancelloria; } \\
\text { Parvancorina; } \\
\text { Charniodiscus; } \\
\text { Cyclomedusa;Choia }\end{array}$ & $\begin{array}{c}\text { Classificação taxonômica, } \\
\text { interpretação paleoambiental }\end{array}$ & Dissertação & $\begin{array}{c}\text { Microanálise semi- } \\
\text { quantitativa (EDS) ao } \\
\text { microscópio eletrônico } \\
\text { de varredura }\end{array}$ \\
\hline
\end{tabular}

1. Formação Tamengo, Grupo Corumbá, Brasil; 2. Formação Guaicurus, Grupo Corumbá, Brasil; 3. Formação Campo Alegre, Bacia do Itajaí, Brasil; 4. Formação Tagatiya Guazu, Grupo Itapucumi, Paraguai; 5. Formação Loma Negra, Grupo Sierras Bayas, Argentina; 6. Formação Yerbal, Grupo Arroyo del Soldado, Uruguai; 7. Formação Polanco, Grupo Arroyo Del Soldado, Uruguai. 
No Brasil, as primeiras ocorrências de Cloudina foram encontradas na Formação Tamengo (Grupo Corumbá), aflorante na pedreira Saladeiro (Ladário MS), por Beurlen e Sommer (1957). O Grupo Corumbá inicia-se com conglomerados arenitos e pelitos da Formação Cadiueus, gradando para arenitos, pelitos e carbonatos da Formação Cerradinho. Estes, por sua vez, passam para dolomitos e pelitos subordinados da Formação Bocaina, que é recoberta pelos calcários e folhelhos carbonosos da Formação Tamengo e estes pelos pelitos da Formação Guaicurus no topo do Grupo.
Inicialmente, os fósseis foram descritos como Aulophycus lucianoi, por terem sido interpretados como algas. Posteriormente, Zaine e Fairchild (1985) e Hahn e Pflug (1985) constataram, independentemente, a similaridade entre A. lucianoi, da Formação Tamengo, e o gênero Cloudina Germs (1972) (Grupo Nama, Namíbia). Subsequentemente, ambos os trabalhos propuseram que os fósseis pertenceriam a esse gênero. Porém, o trabalho de Zaine e Fairchild (1985) propôs a combinação nova Cloudina lucianoi, enquanto Hahn e Pflug (1985) criaram um nome novo para a espécie, Cloudina waldei. Zaine e Fairchild (1987) colocaram C. waldei como

Tabela 2. Trabalhos realizados com fósseis de metazoários ediacaranos na América do Sul.

\begin{tabular}{|c|c|c|c|c|c|}
\hline Referência & $\begin{array}{l}\text { Unidade } \\
\text { geológica }\end{array}$ & Fóssil(eis) & Tipo de estudo & $\begin{array}{l}\text { Tipo de } \\
\text { trabalho }\end{array}$ & $\begin{array}{c}\text { Métodos aplicados } \\
\text { à análise dos } \\
\text { fósseis }\end{array}$ \\
\hline Babcock et al. (2005) & 1 & Corumbella werneri & $\begin{array}{c}\text { Reinterpretação } \\
\text { morfológica e afinidades } \\
\text { filogenéticas. Considerações } \\
\text { paleobiogeográficas e } \\
\text { paleoecológicas }\end{array}$ & Artigo & - - - - - - - \\
\hline Gaucher et al. (2005) & 5 e 7 & $\begin{array}{l}\text { Cloudina cf. C. } \\
\text { riemkeae; Cloudina } \\
\text { riemkeae }\end{array}$ & $\begin{array}{l}\text { Classificação taxonômica e } \\
\text { correlações (bio)estratigráficas }\end{array}$ & Artigo & $-\ldots-\ldots$ \\
\hline Gaucher et al. (2003) & 1 & Cloudina Iucianoi & $\begin{array}{c}\text { Classificação taxonômica e } \\
\text { interpretações paleoecológicas } \\
\text { e paleogeográficas }\end{array}$ & Artigo & $-\cdots-\ldots$ \\
\hline $\begin{array}{l}\text { Boggiani e Gaucher } \\
\text { (2004) }\end{array}$ & 4 & Cloudina Iucianoi & $\begin{array}{l}\text { Relato de ocorrência do } \\
\text { fóssil, correlação e idades da } \\
\text { unidade litológica }\end{array}$ & Resumo & - - - - - - - \\
\hline $\begin{array}{l}\text { Gaucher e } \\
\text { Sprechmann (1999) }\end{array}$ & 6 & $\begin{array}{l}\text { C. riemkeae,W. } \\
\text { marburgensis;S. } \\
\text { siderophoba }\end{array}$ & $\begin{array}{l}\text { Descrição sistemática e } \\
\text { interpretações paleobiológicas }\end{array}$ & Artigo & $\begin{array}{l}\text { Espectroscopia de } \\
\text { Energia Dispersiva } \\
\text { de Raios-x (EDS ou } \\
\text { EDX) }\end{array}$ \\
\hline $\begin{array}{l}\text { Gaucher e } \\
\text { Sprechmann (1998) }\end{array}$ & 6 & Cloudina riemkeae & $\begin{array}{c}\text { Relato de ocorrência do } \\
\text { fóssil, correlação e idades da } \\
\text { unidade litológica }\end{array}$ & $\begin{array}{l}\text { Resumo } \\
\text { expandido }\end{array}$ & $-\cdots-\ldots$ \\
\hline Paim et al. (1997) & 3 & Chancelloria & $\begin{array}{l}\text { Classificação taxonômica e } \\
\text { inferências biocronológicas }\end{array}$ & $\begin{array}{l}\text { Nota } \\
\text { científica }\end{array}$ & - - - - - - - - \\
\hline Zaine (1991) & 1 & $\begin{array}{l}\text { Cloudina lucianoi, } \\
\text { Corumbella werneri }\end{array}$ & $\begin{array}{l}\text { Classificação taxonômica e } \\
\text { considerações filogenéticas }\end{array}$ & Tese & $-\ldots-\ldots$ \\
\hline Zaine e Fairchild (1987) & 1 & $\begin{array}{l}\text { Cloudina lucianoi, } \\
\text { Corumbella werneri }\end{array}$ & $\begin{array}{c}\text { Descrição sistemática e } \\
\text { considerações filogenéticas }\end{array}$ & $\begin{array}{l}\text { Resumo } \\
\text { expandido }\end{array}$ & $-\ldots-\ldots$ \\
\hline Zaine e Fairchild (1985) & 1 & Cloudina Iucianoi & $\begin{array}{c}\text { Considerações taxonômicas e } \\
\text { filogenéticas }\end{array}$ & Resumo & $-\ldots-\ldots$ \\
\hline Hahn e Pflug (1985) & 1 & Cloudina waldei & $\begin{array}{c}\text { Descrição sistemática e } \\
\text { posicionamento sistemático }\end{array}$ & Artigo & - - - - - - - \\
\hline Hahn et al. (1982) & 1 & $\begin{array}{c}\text { Corumbella werneri } \\
\text { nov. sp. }\end{array}$ & $\begin{array}{c}\text { Descrição sistemática e } \\
\text { interpretações morfológicas } \\
\text { e filogenéticas }\end{array}$ & Artigo & $-\ldots-\ldots$ \\
\hline Walde et al. (1982) & 1 & Corumbella werneri & $\begin{array}{c}\text { Estudo morfológico e } \\
\text { considerações filogenéticas }\end{array}$ & Resumo & - - - - - - - \\
\hline
\end{tabular}

1. Formação Tamengo, Grupo Corumbá, Brasil; 2. Formação Guaicurus, Grupo Corumbá, Brasil; 3. Formação Campo Alegre, Bacia do Itajaí, Brasil; 4. Formação Tagatiya Guazu, Grupo Itapucumi, Paraguai; 5. Formação Loma Negra, Grupo Sierras Bayas, Argentina; 6. Formação Yerbal, Grupo Arroyo del Soldado, Uruguai; 7. Formação Polanco, Grupo Arroyo Del Soldado, Uruguai. 
sinônimo júnior de C. lucianoi, pois “(...) Cloudina waldei (...) é indistinguível de Aulophycus lucianoi, portanto um sinônimo júnior e inválido segundo o Código Internacional de Nomenclatura Zoológica". Contrariando essa proposição de sinonímia, Conway Morris et al. (1990) argumentou que como o fóssil foi considerado de origem algálica, "Aulophycus lucianoi" não estaria no âmbito da International Commission on Zoological Nomenclature (ICZN) e Cloudina waldei seria a nomenclatura considerada válida. Zaine (1991) citou o artigo 10.f do ICZN (1985) no qual "para um organismo inicialmente não classificado como animal, mas assim classificado posteriormente, o nome original continua disponível, desde que publicado de forma válida pelo código que regeu seu estabelecimento".

Após as descrições iniciais e as controvérsias com relação à nomenclatura de Cloudina do Grupo Corumbá, Zaine (1991) observou alguns aspectos tafonômicos da preservação desses fósseis, como a presença de fragmentos de conchas de Cloudina dentro desses organismos, presença de franja fibro-radiada ao redor das conchas, comportamento dúctil e rúptil dos fósseis e a distribuição de tamanho entre 0,2 e 3,8 mm de diâmetro, de conchas analisadas em seções delgadas. Posteriormente, tendo

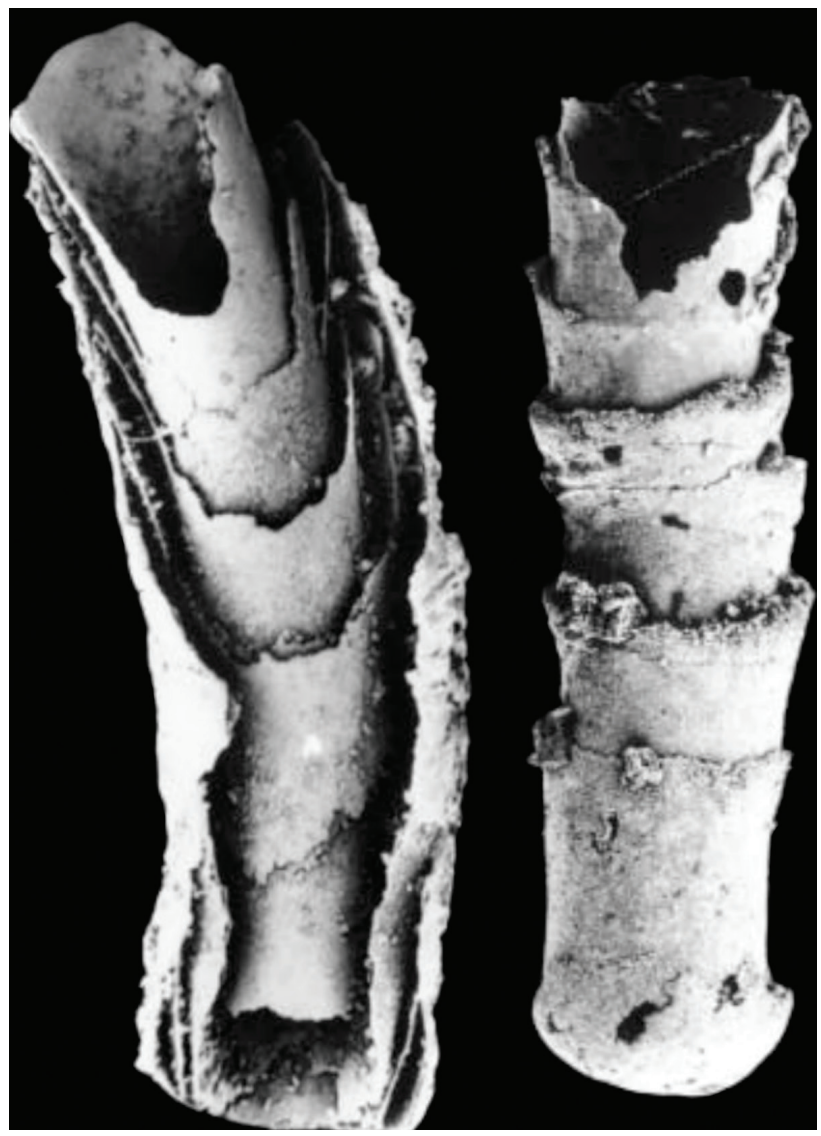

Figura 4. Microscopia eletrônica de varredura, mostrando o tubo calcário de Cloudina com a estrutura "funil-emfunil" (Hua et al., 2005). em vista a escassez de trabalhos sobre Cloudina, no Grupo Corumbá, Meira (2011) detalhou os conhecimentos tafonômicos, deposicionais e estratigráficos desses fósseis, aumentando, inclusive, a zona estratigráfica de ocorrência do fóssil para a Formação Guaicurus. Além disso, Meira (2011) também descreveu uma possível nova espécie de Cloudina.

O gênero Cloudina também foi encontrado em outras três localidades na América do Sul. No nordeste do Paraguai (Grupo Itapucumi), Boggiani e Gaucher (2004) encontraram restos de Cloudina.

O Grupo Itapucumi compreende, da base para o topo, a Formação Vallemi (arenitos e siltitos), Formação Camba Jhopo (carbonatos oolíticos e dolomitos) e a Formação Cerro Curuzo (margas e pelitos). A Formação Camba Jhopo é lateralmente equivalente à fossilífera Formação Taguatiya Guazu, na qual foram documentados os fósseis. Essa formação é composta principalmente de calcários grainstones que gradam para fácies heterolíticas de grainstones e argilitos calcários. A espécie relatada foi Cloudina lucianoi, identificada pela frequência de diâmetro entre 0,1 e $3,5 \mathrm{~mm}$. É encontrada sob três modos principais de preservação, como coquinas, bioclastos finos ou conchas associadas com trombólitos. Essa última é a forma mais comum de preservação de Cloudina em outras localidades do planeta e indica os habitats desses organismos, uma vez que, quando encontrados associados com trombólitos, eles apresentam-se articulados e prostrados, com preservação in situ (Warren et al., 2011).

Cloudina também foi encontrada no Uruguai por Gaucher e Sprechmann (1998) e Gaucher e Sprechmann (1999). Os fósseis foram encontrados na Formação Yerbal do Grupo Arroyo del Soldado e foram atribuídos a uma das espécies de menor tamanho do gênero Cloudina, C. riemkeae. Esses fósseis apresentaram características não encontradas anteriormente para a espécie, como espinhos e brotamento. Mais recentemente, Cloudina riemkeae também foi registrada na Formação Polanco (Gaucher et al., 2005). Gaucher et al. (2005), correlacionando o Grupo Arroyo del Soldado (Uruguai) ao Grupo Sierras Bayas (Argentina), divulgaram, de forma preliminar, a presença do gênero Cloudina na Formação Loma Negra, Grupo Sierra Bayas. O Grupo Sierra Bayas, que tem apenas $350 \mathrm{~m}$ de espessura, é composto da base para o topo pela Formação Villa Mónica (arenitos e dolomitos estromatolíticos), Formação Cerro Largo (diamictitos e lamitos, arenitos e folhelhos) e Formação Loma Negra (calcários micríticos ricos em matéria orgânica). Essa última formação, apesar de não apresentar microfósseis, tem fósseis tubulares que foram atribuídos a Cloudina cf. riemkeae pelos autores. Esses espécimes têm parede calcítica, diâmetro máximo entre 0,15 e $0,80 \mathrm{~mm}$ e comprimento de até $2,5 \mathrm{~mm}$. A presença desse táxon na Formação Loma Negra é uma evidência adicional para a proposta de correlação do Grupo Arroyo del Soldado com o Grupo Sierras Bayas. 


\section{Corumbella werneri (Hahn et al., 1982)}

Corumbella werneri (Figura 5) foi, inicialmente, documentada na pedreira calcária Saladeiro, da Companhia de Cimento Itaú, situada nos limites dos municípios de Corumbá e Ladário, em Mato Grosso do Sul (Hahn et al., 1982; Walde et al., 1982). Em Corumbá, Corumbella ocorre na mesma formação que o fóssil Cloudina, porém, diferentemente deste, os fósseis de $C$. werneri não ocorrem em carbonato, mas em margas e folhelhos. Outros registros também foram observados nos arenitos de Great Basin (membro inferior da Formação Wood Canyon, EUA, Hagadorn e Waggoner, 2000) e nos grainstones e mudstones do Grupo Itapucumi (Paraguai, Warren et al., 2011; 2012).

As primeiras descrições e interpretações sistemáticas e paleoecológicas desse táxon foram realizadas por Hahn et al. (1982), que reconheceram tetrameria em uma estrutura de tubo peridérmico bipartite, composta por uma região proximal ou pólipo primário, sem região de base de ancoragem evidente; e uma distal, ou polipário, estruturada por um arranjo bisseriado de pólipos secundários.

Estudos recentes designaram seguramente $C$. werneri ao filo Cnidaria, classe Schyphozoa, com afinidades com conulários e coronados (Babcock et al., 2005; Pacheco et al., 2010b; Pacheco et al., 2011c; Pacheco et al., 2011b; Pacheco, 2012). Enquanto alongados, estreitos, anelados e articuláveis, os tubos de $C$. werneri encerram características similares aos cifístomas dos coronados. Por outro lado, esse fóssil compartilha maior número de atributos com os conularídeos, tais como geometria piramidal, seção transversal quadrangular, linhas medianas, espessamentos internos,

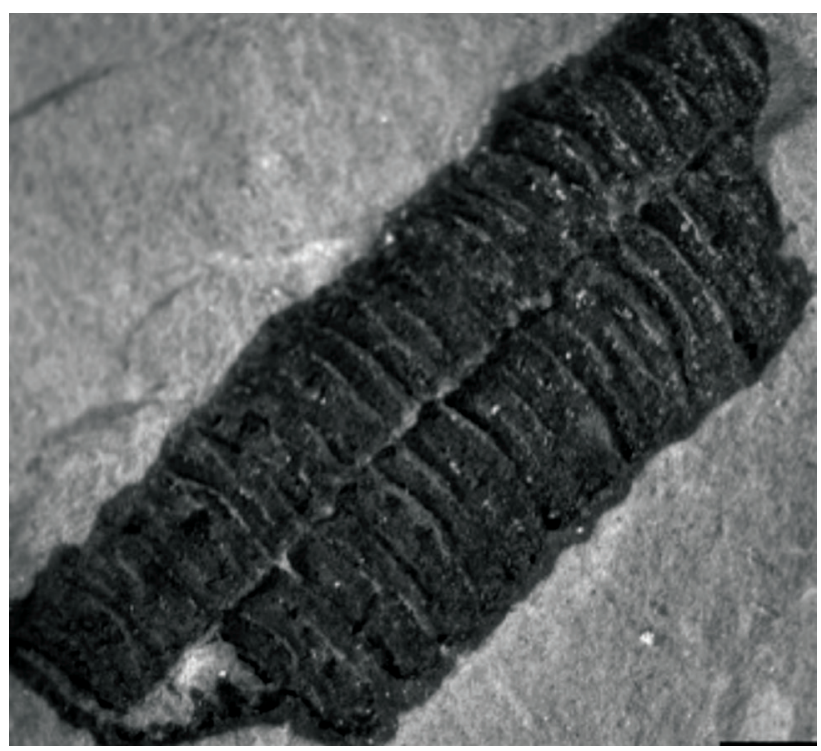

Figura 5. Corte longitudinal da carapaça de Corumbella werneri (Pacheco, 2012). faces, bordas laterais (denominadas arestas em conulários) e disposição dos anéis nas faces de modo similar aos cordões (Figuras 5 e 6) (Pacheco et al., 2010a, 2010b; Pacheco et al., 2011c; Pacheco, 2012). Os atributos de Corumbella até agora compilados podem remeter as afinidades desse táxon aos grupos dos mais antigos conulários paleozoicos (Yi et al., 1997) e neoproterozoicos afins (Ivantsov e Fendokin, 2002; Van Iten et al., 2013).

Por outro lado, as características até o momento evidenciadas em Corumbella não foram suficientes para estabelecer, com maior precisão, as relações filogenéticas entre os Scyphozoa para esse táxon. Babcock et al. (2005) se apoiaram na ausência de um estágio medusoide para o maior detalhamento na taxonomia desse fóssil.

Corumbella está entre os primeiros metazoários a realizar esqueletogênese orgânica ou, ao menos, fracamente mineralizada (Pacheco et al., 2011; Warren et al., 2012) e as conchas de Cloudina representam o mais antigo animal com esqueleto biomineralizado, com evidentes marcas de predação (Bengtson e Zhao, 1992; Hua et al., 2003). Nesse sentido, os metazoários Neoediacaranos do Grupo Corumbá refletem grande importância no estabelecimento das relações ecológicas e suas consequências nas inovações morfológicas e diversidade biológica (Warren et al., 2012).

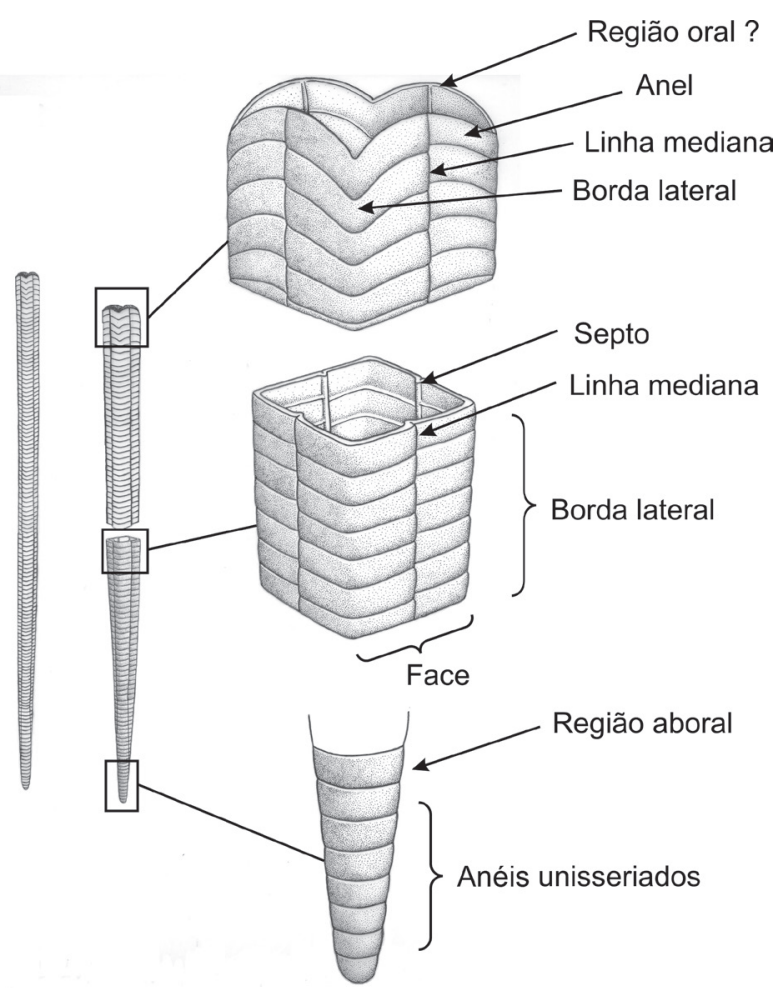

Figura 6. Modelo proposto para geometria e estruturas (internas e externas) para o tubo de Corumbella werneri (modificado de Pacheco et al., 2011). 


\section{Outros metazoários}

\section{Waltheria marburgensis (Gaucher e Sprechmann, 1999)}

Gaucher e Sprechmann (1999) caracterizaram W. marburgensis como uma concha cônico-tubular reta, alongada e septada, com diâmetro variando entre 10 micrômetros e 1 milímetro e comprimento entre 0,8 e $8 \mathrm{~mm}$. A concha tem três camadas: uma interna com septos, uma mediana helicoidal e uma externa que pode estar substituída por quartzo. Em análise de espectroscopia de Energia Dispersiva de Raios-X (EDX ou EDS) foi demonstrada a possível presença de fósforo $(\mathrm{P})$ e traços de cálcio $(\mathrm{Ca})$, sugerindo que a composição original da carapaça fosse, provavelmente, fosfato-calcítica. Em uma das extremidades do fóssil há uma câmara esférica com um prolongamento basal cilíndrico, enquanto que a outra extremidade provavelmente era aberta no organismo. Alguns espécimes têm ramificação na concha, o que pode representar um de seus modos de reprodução, provavelmente assexuado. A complexidade da concha e a natureza fosfática da parede levaram os autores a interpretarem esse fóssil como um provável metazoário basal. W. marburgensis, que é o fóssil mais comum das sequências siliciclásticas da Formação Yerbal do Grupo Arroyo del Soldado (Uruguai), pode ser encontrado sob dois modos de fossilização, hematização completa ou seletiva da concha (Gaucher e Sprechmann, 1999).

\section{Soldadotubulus siderophoba (Gaucher e Sprechmann, 1999)}

A morfologia geral do fóssil de $S$. siderophoba, segundo Gaucher e Sprechmann (1999), é semelhante à Waltheria marburgensis. É composto de tubos cônicos, não ramificados, retos a aproximadamente curvos, com diâmetro interno entre 30 e 67 micrômetros e comprimento total dos espécimes variando entre 0,2 e $0,6 \mathrm{~mm}$. A extremidade oral apresenta uma câmara de formato cilíndrico com diâmetro maior do que do tubo $(29-75 \mu \mathrm{m})$ e estrias perpendiculares ao eixo longitudinal. Por vezes, a câmara pode estar presente em porções medianas ou na outra extremidade dos tubos. Sua similaridade com W. marburgensis pode representar uma afinidade filogenética entre os dois táxons, segundo os autores. Soldadotubulus também compõe a assembleia encontrada em siliciclastos da Formação Yerbal do Grupo Arroyo del Soldado (Gaucher e Sprechmann, 1999).

\section{Chancelloria (Walcott, 1920)}

Chancelloria pode ser identificada pela presença de escleritos conectados entre si por meio de 6 a 8 raios tangenciais, constituindo uma rede de formato triangular ou quadrangular (Paim et al., 1997; Leipnitz et al., 1997; Zucatti da Rosa, 2005). Os discos centrais dos escleritos têm cerca de 1 a $3 \mathrm{~mm}$ de diâmetro. Os fósseis foram encontrados na Formação Campo Alegre da Bacia do Itajaí, aflorante no leste do estado de Santa Catarina (Paim et al., 1997; Zucatti da Rosa, 2005). Os espécimes são encontrados como moldes e impressões e não há evidências de biomineralização. Em comparação com os Chancellorida do Cambriano é possível que os encontrados na Formação Campo Alegre não sejam esponjas, mas sim tapetes microbianos especializados (Zucatti da Rosa, 2005). A presença desses organismos, além de icnofósseis típicos, indica uma idade Cambriana Inferior à Cambriana Média para a Bacia do Itajaí (Conway Morris e Menge, 1992; Netto e Zucatti da Rosa, 1997), ao contrário das evidências de datação pelo método $\mathrm{Pb} / \mathrm{U}$, que sugerem idades entre $606 \mathrm{e}$ $632 \mathrm{Ma}$ (Silva et al., 2002).

\section{Choia (Walcott, 1920)}

Choia é um fóssil de formato circular ou ovalado, encontrado preservado como moldes na Formação Campo Alegre, na Bacia do Itajaí (Zucatti da Rosa, 2005). Do centro do fóssil partem vários raios retilíneos que são interpretados como espículas de um possível porífero. Os raios mais curtos formam uma "coroa interna" de diâmetro entre 6 e $8 \mathrm{~mm}$. Os raios mais alongados são menos numerosos e têm diâmetros de até $14 \mathrm{~mm}$. Além de Chancelloria, Choia também é um organismo típico do Cambriano.

\section{Discos}

As formas circulares, ou discos, bem comuns nas biotas do Ediacarano, também ocorrem na Bacia do Itajaí (Zuccatti da Rosa, 2005). Os fósseis encontrados foram atribuídos aos gêneros Cyclomedusa e Charniodiscus. Ambos apresentam dois círculos concêntricos, mas diferem morfologicamente no tamanho: Cyclomedusa tem $15 \mathrm{~mm}$ de diâmetro, enquanto que Charniodiscus apresenta $40 \mathrm{~mm}$; e na presença de 6 saliências no circulo interno de Charniodiscus, além de uma impressão alongada sob seu disco. Essas últimas características estão ambas ausentes em Cyclomedusa. As afinidades biológicas dos discos são motivo de debate, existindo grande divergência entre interpretações dos autores, motivo pelo qual o termo "medusoide" (referente às medusas do Filo Cnidaria) não é apropriado para designar esses fósseis. Atualmente, acredita-se que se trata de um grupo polifilético, mas, mesmo assim, pode ser que algumas formas circulares estejam relacionadas aos animais (Glaessner, 1984). 


\section{Parvancorina (Glaessner, 1958)}

Zuccatti da Rosa (2005) documentou a presença do gênero ediacarano Parvancorina que também provém da Formação Campo Alegre (Bacia do Itajaí). Sua morfologia triangular lembra o formato de uma ferradura alongada e fechada. Seu comprimento varia entre 8 e $11 \mathrm{~mm}$ e sua largura entre 5 e $7 \mathrm{~mm}$. Suas bordas são consistentes e há uma elevação longitudinal na porção mediana (Zucatti da Rosa, 2005). Suas afinidades ainda não são muito compreendidas, mas existe a possibilidade de que esse organismo estaria relacionado aos artrópodes (Glaessner, 1980). Parvancorina é um organismo típico da biota ediacarana da assembleia White Sea.

No Brasil, a presença de registros fósseis ediacaranos na Bacia do Itajaí apresenta implicações evolutivas importantes para o entendimento do alvorecer da vida animal na Terra, uma vez que pode constituir o segundo registro da biota de Ediacara datado do mesmo período no mundo (Yuan et al., 2011). Esses fósseis constituem possíveis vendobiontes, espongiários e cnidários, além de icnofósseis, de um modo bem similar ao que já foi descrito para a biosfera ediacarana (Xiao e Laflamme, 2009). Estudos dessas assembleias de organismos de corpo mole correlacionados com os dados de metazoários capazes de realizar esqueletogênese, evidenciados no Grupo Corumbá (Meira, 2011; Pacheco et al., 2011c; Pacheco et al., 2011a) e no Paraguai (Warren et al., 2012) podem servir como subsídio na elucidação dos fatores que culminaram na extinção dos vendobiontes e dos grupos de animais sem precedentes modernos e das condições para o estabelecimento da fauna subsequente no Fanerozoico.

\section{PERSPECTIVAS FUTURAS}

O uso de técnicas não destrutivas de alta resolução tem se revelado importante para o estudo dos fósseis de metazoários ediacaranos no Brasil, ainda com especial ênfase para Corumbella (Pacheco et al., 2011a; Pacheco e Leme, 2011; Pacheco, 2012). No caso desse cifozoário ainda não é possível afirmar se sua carapaça foi completamente orgânica (tal como a periderme dos coronados atuais), ou, ao menos, fracamente biomineralizada (tal como as tecas quitino-fosfatizadas dos conulários) (Pacheco et al., 2011a; Warren et al., 2012). Utilizando-se a infraestrutura disponível no Laboratório de Astrobiologia (USP) e no Instituto de Química (USP) e em colaboração com o Laboratório Nacional de Luz Síncrotron (LNLS) de Campinas e com a UNIVAP, o uso de técnicas como espectroscopia Raman e fluorescência de raios X tem auxiliado tanto na elucidação da composição química dos tegumentos de invertebrados fósseis, tais como Corumbella, como no entendimento dos processos de fossilização e paleoambiente. Essas mesmas técnicas vêm sendo utilizadas na interpretação do ambiente onde se deu a evolução de eucariontes unicelulares Pré-Cambrianos, em um evento de fosfogênese mundial que precede o registro brasileiro dos primeiros invertebrados capazes de realizar esqueletogênese (Morais et al., 2012). Fósseis brasileiros de Corumbella também foram submetidos a técnicas de microtomografia de raios X (microCT) na Universidade Técnica de Munique e em colaboração com o European Synchrotron Radiation Facility (ESRF) (Grenoble, França) para observação e reconstituição tridimensional de suas estruturas internas e outras partes obliteradas pela matriz rochosa (e.g. região aboral) que se revelam imprescindíveis para o estudo da morfologia, da ecologia e da evolução desses animais. Nesse sentido, essas técnicas de alta resolução inauguram uma nova e mais completa perspectiva para o estudo dos paleoinvertebrados no Brasil.

Essa nova perspectiva metodológica será capaz de produzir conhecimentos adicionais indispensáveis na compreensão do evento evolutivo ocorrido no Período Ediacarano, o surgimento da biomineralização. Além de Corumbella, este momento evolutivo é bem marcado mundialmente pelo aparecimento de Cloudina no registro fossilífero: um dos primeiros animais capaz de sintetizar conchas carbonáticas. Já estão sendo utilizadas as técnicas de espectroscopia Raman, fluorescência de raios $\mathrm{X}$ e microtomografia de raios $\mathrm{X}$ para auxiliar na compreensão dos processos envolvidos na biomineralização de Cloudina. Ainda existem outras questões relevantes a serem solucionadas para esse organismo, como suas afinidades filogenéticas e a validez taxonômica das espécies que compõem esse gênero.

No caso dos organismos encontrados no Grupo Arroyo del Soldado (Uruguai), essas técnicas tornamse ainda mais significativas. São fósseis de organismos que, além de também pertencerem aos primeiros animais biomineralizadores, foram pouco estudados — desde sua descrição original (Gaucher e Sprechmann, 1999) não há nenhum estudo com esses fósseis. Para Waltheria marburgensis foi testemunhada a possível presença de cálcio e fósforo na composição de sua concha, enquanto que Soldadotubulus siderophoba tem concha de composição desconhecida (Gaucher e Sprechmann, 1999). Análises de XRF serão úteis para comparação com as já feitas pelo método de EDX. As duas técnicas têm os mesmos princípios, mas como a sensibilidade das análises varia entre elas, a comparação dos resultados obtidos de ambas poderá ser muito útil na interpretação da composição elementar das conchas desses dois prováveis metazoários. É importante ressaltar que a posição taxonômica dessas duas espécies ainda não pode ser determinada com precisão, até mesmo no nível de Reino. 
Os fósseis da Bacia do Itajaí (Chancelloria, Choia, Parvancorina, Cyclomedusa e Charniodiscus) foram encontrados sob a forma de impressões e moldes. Esse tipo de preservação é típico da biota ediacarana que não tinha partes duras. Uma vez que esses organismos, muito provavelmente, não eram biomineralizadores, as técnicas de XRF e Raman poderão ser utlizadas para interpretações paleoambientais. A biota encontrada na Bacia do Itajaí, se comprovada a idade Ediacarana, será de grande importância para a compreensão do Período Ediacarano, uma vez que representaria o primeiro registro de fósseis típicos da assembleia White Sea na América do Sul e também seria o primeiro registro de Chancelloria e Choia nesse Período.

Para Darwin (1859), uma das contraposições à sua teoria da evolução por seleção natural era o surgimento repentino de diversos grupos de animais em apenas alguns milhões de anos, um piscar de olhos em termos geológicos, logo no Cambriano. Algumas décadas atrás, a descoberta da biota ediacarana parecia ter resolvido essa questão dos precursores animais. Contudo, a partir da década de 1980, outra visão dos fósseis ediacaranos típicos é proposta: os vendobiontes. Atualmente, as interpretações sobre as afinidades taxonômicas de muitos fósseis ediacaranos são controversas, mas é possível que muitos desses organismos não pertencessem aos animais verdadeiros. Porém, mesmo entre vendobiontes, algas e protistas, no Período Ediacarano estavam presentes, de fato, os primeiros metazoários. Dessa forma, o estudo dos fósseis ediacaranos de metazoários, ainda mais por meio de técnicas modernas, como XRF, Raman e microtomografia, podem fornecer indícios para interpretações mais acuradas sobre os primeiros estágios evolutivos do Reino Metazoa há cerca de 635-541 milhões de anos e sua relação com a posterior "Explosão Cambriana".

\section{REFERÊNCIAS}

Antcliffe, J. B., Gooday, A. J., Brasier, M. D. (2011). Testing the protozoan hypothesis for ediacaran fossils: a developmental analysis of Palaeopascichnus. Palaeontology, 54(5), 1157-1175. DOI: 10.1111/j.1475-4983.2011.01058.x.

Babcock, L. E., Grunow, A. M., Sadowski, G. R., Leslie, S. A. (2005). Corumbella, an Ediacaran-grade organism from the Late Neoproterozoic of Brazil. Palaeogeography, Palaeoclimatology, Palaeoecology, 220, p. 7-18, 2005. DOI: 10.1016/j.palaeo.2003.01.001

Bengston, S. (1994). The advent of animal skeletons. In: Bengston, S. Early life on Earth (Nobel Symposium no. 84, 412-425). USA: Columbia University Press.
Bengtson, S., Zhao, Y. (1992). Predatorial borings in late Precambrian mineralized exoskeletons. Science, 257, 367-369.

Beurlen, K.; Sommer, F. W. (1957). Observações estratigráficas e paleontológicas sobre o calcário Corumbá. Rio de Janeiro, Departamento Nacional da Produção Mineral/Divisão de Geologia e Mineralogia: Boletim 168, p. 35.

Boggiani, P. C., Gaucher, C. (2004). Cloudina from the Itapucumi Group (Vendian, Paraguay): age and correlations. In: Symposium on Neoproterozoic - Early Paleozoic Events in Sw-Gondwana, São Paulo: IGCP Project 478, 13-15.

Bottjer, D. J., Hagadorn, J. W., Dornbos, S. Q. (2000). The Cambrian substrate revolution. GSA Today, 10(9), 1-7.

Buss, L. W., Seilacher, A. (1994). The Phylum Vendobionta: a sister group of the Eumetazoa? Paleobiology, 20, 1-4.

Conway Morris, S., Mattes, B. W., Menge, C. (1990). The early skeletal organism Cloudina: new occurrences from Oman and possibly China. American Journal of Science, 290-A, 245-260.

Conway Morris, S., Menge, C. (1992). Carinachitiids, Hexagulaconulariids, and Puntactus: Problematic metazoans from the Early Cambrian of South China. Journal of Paleontology, 66(3), 384-406.

Conway Morris, S., Robison, R. A. (1986). Middle Cambrian priapulids and other soft-bodied fossils from Utah and Spain. University of Kansas Paleontological Contributions, 17, 1-22.

Crimes, T. P. (1987). Trace fossils and correlation of late Precambrian and Early Cambrian strata. Geological Magazine, 124, 97-119.

Crimes, T. P. (1989). Trace fossils. In: Cowie, J. W.; Brasier, M. D. The Precambrian-Cambrian Boundary. Oxford Monographs on Geology and Geophysics, 12, 166-195.

Darwin, C. (1859). The origin of species by means of natural selection, or the preservation of favoured races in the struggle for life. London: John Murray.

Dzik, J. (2007). The Verdun Syndrome: simultaneous origin of protective armour and infaunal shelters at the PrecambrianCambrian transition. In: Vickers-Rich, P.; Komarower, P. The Rise and Fall of the Ediacaran Biota. Geological Society of London, special publication, 286, 405-414. 
Fedonkin, M. A. (1987). Non-skeletal fauna of the Vendian and its place in the evolution of metazoans. Trudy of the Paleontological Institute, Akademia Nauk SSSR, 226, 1-173.

Fedonkin, M. A., Simonetta, A.; Ivantsov, A. Y. (2007). New data on Kimberella, the Vendian mollusk-like organism (White Sea region, Russia): palaeoecological and evolutionary implications. In: Vickers-Rich, P.; Komarower, P. The Rise and Fall of the Ediacaran Biota. Geological Society of London, special publication, 286, 157-179.

Gaucher, C., Boggiani, P. C., Sprechmann, P., Sial, A. N., Fairchild, T. R. (2003). Integrated correlation of the Vendian to Cambrian Arroyo del Soldado and Corumbá Groups (Uruguay and Brazil): palaeogeography, palaeoclimatic and palaeobiology implications. Precambrian Research, $120,241-278$.

Gaucher, C., Poiré, D. G., Gómez Peral, L., Chiglino, L. (2005). Litoestratigrafía, bioestratigrafía y correlaciones de las sucesiones sedimentarias del NeoproterozoicoCámbrico del Cratón del Rio de la Plata (Uruguay y Argentina). Latin American Journal of Sedimentology and Basin Analysis, 12(2), 145-160.

Gaucher, C., Sprechmann, P. (1998). Grupo Arroyo Del Soldado: paleontologia, edad y correlaciones (VendianoCámbrico Inferior, Uruguay). In: II Congreso Uruguayo de Geología, Montevideo:Ministerio de Industria, Energía y Minería, 183-187.

Gaucher, C., Sprechmann, P. (1999). Upper Vendian skeletal fauna of the Arroyo del Soldado Group, Uruguay. Beringeria, 23, 55-91.

Germs, G. J. B. (1972). New shelly fossils from Nama Group, South West Africa. American Journal of Science, 272, 752-761.

Glaessner, M. F. (1980). Parvancorina - an arthropod from the Late Precambrian (Ediacarian) of South Australia. Annalen des Naturhistorisches Museum in Wien, 83, 83-90.

Glaessner, M. F. (1983). The emergence of metazoa in the early history of life. Precambrian Research, 20, 427-441.

Glaessner, M. F. (1984). The Dawn of Animal Life. Cambridge: Cambridge University Press.
Hahn, G., Hahn, R., Leonardos, O. H., Pflug, H. D., Walde, D. H. G. (1982). Kfrperlich erhaltene ScyphozoenReste aus dem Jungprekambrium Brasiliens. Geologica et Paleontologica, 16, 1-18.

Hahn, G., Pflug, H. D. (1985). Die Cloudinidae n. fam., Kalk-Röhren aus dem Vendium und Unter-Kambrium. Senckenbergiana Lethaea, 65, 413-431.

Hua, H., Chen Z., Yuan X., Zhang L., Xiao S. (2005). Skeletogenesis and asexual reproduction in the earliest biomineralizing animal Cloudina. Geology, 33(4), 277-280.

Hua, H., Pratt, B. R., Zhang, L. Y. (2003). Borings in Cloudina shells: complex predator-prey dynamics in the terminal Neoproterozoic. Palaios, 18, 454-459.

Ivantsov, A. Y., Fedonkin, M. A. (2002). Conulariid-like fossil from the Vendian of Russia: a metazoan clade across the Proterozoic/Palaeozoic boundary. Palaeontology, 45, 1219-1229.

Jenkins, R. J. F. (1984). Ediacaran events: boundary relationships and correlation of key sections, especially in 'Armorica'. Geological Magazine, 121, 635-643.

Kimura, H., Watanabe, Y. (2001). Oceanic anoxia at the Precambrian-Cambrian boundary. Geology, 29(11), 995-998.

Laflamme, M., Xiao, S., Kowalewski, M. (2009). Osmotrophy in modular Ediacara organisms. Proceedings of the National Academy of Sciences of United States of America, 106(34), p. 14438-14443, 2009. DOI: 10.1073/ pnas.0904836106.

Leipnitz, I. I., Paim, P. S. G., Da Rosa, A. A. S., Zucatti Da Rosa, A. L., Nowatzki, C. H. (1997). Primeira ocorrência de Chancelloriidae no Brasil. In: XV Congresso Brasileiro de Paleontologia, v. 1, p. 1. São Pedro: SBP.

Meira, F. V. E. Caracterização tafonômica e estratigráfica de Cloudina lucianoi (Beurlen \& Sommer, 1957) Zaine \& Fairchild, 1985, no Grupo Corumbá, Ediacarano do sudoeste do Brasil. 2011. Dissertação (Mestrado). São Paulo: Instituto de Geociências - USP.

Morais, L. P. S., Pacheco, M. L. A. F., Sanchez, E. A. M., Bendia, A. G., Fontaneta, G. T., Fairchild, T. R., Boggiani, P. C., Leme, J. M. (2012). The rise of heterotrophic eukaryotic 
cells: when the Brazilian vase-shaped microfossils came out to the complexity of life. FERMOR, 2012. Submetido.

Narbonne, G. M. (1998). The Ediacara biota: a terminal Neoproterozoic experiment in the evolution of life. GSA Today, 8, 1-6.

Narbonne, G. M. (2004). Modular construction of early Ediacaran complex life forms. Science, 305, 1141-1144.

Narbonne, G. M. (2005). The Ediacara biota: Neoproterozoic origin of animals and their ecosystems. Annual Reviews of Earth and Planetary Sciences, 33, 421442. DOI: 10.1146/annurev.earth.33.092203.122519.

Netto, R. G., Zucatti Da Rosa, A. L. (1997). Registro icnofossilífero da Bacia do Itajaí, SC: Uma primeira visão. In: XV Congresso Brasileiro de Paleontologia, 136, 136, São Pedro: SBP.

Pacheco, M. L. A. F. (2012). Reconstituição morfológica e análise sistemática de Corumbella werneri Hahn et al. 1982 (Formação Tamengo, Ediacarano, Grupo Corumbá), Mato Grosso do Sul, Brasil: implicações paleoecológicas e tafonômicas. 2012. Tese (Doutorado) - São Paulo: Instituto de Geociências (USP).

Pacheco, M. L. A. F., Galante, D., Rodrigues, F., Leme, J. M. (2011a). Corumbella werneri: The rise of animal mineralized skeletons? Activity Report - Brazilian Synchrotron Light Laboratory, 1-2.

Pacheco, M. L. A. F., Leme, J. M. (2011). Raman spectra of the Ediacaran fossil Corumbella werneri Hahn et al. (1982). Sao Paulo Advanced School of Astrobiology, 38-38.

Pacheco, M. L. A. F., Leme, J. M., Fairchild, T. R. (2010a). Reinterpretação de atributos morfológicos de Corumbella werneri Hahn et al. 1982 (Formação Tamengo, Bacia Corumbá, Mato Grosso do Sul) por meio de uma análise tafonômica básica. Paleo SP. In: Reunião Anual da Sociedade Brasileira de Paleontologia, Rio Claro (SP): SBP.

Pacheco, M. L. A. F., Leme, J. M., Fairchild, T. R. (2010b). Re-evaluation of the morphology and systematic affinities of Corumbella werneri Hahn et al. 1982, Tamengo Formation (Ediacaran), Corumbá, Brazil. In: X Congreso Argentino de Paleontología y Bioestratigrafía., VII Congreso Latinoamericano de Paleontología, 193.

Pacheco, M. L. A. F., Leme, J. M., Fairchild, T. R. (2011b). Análise tafonômica de Corumbella werneri Hahn et al. 1982
(Formação Tamengo, Grupo Corumbá, Mato Grosso do Sul): alterações morfológicas e implicações no estabelecimento de afinidades taxonômicas. In: XXII Congresso Brasileiro de Paleontologia, p. 449-452. Natal: SBP.

Pacheco, M. L. A. F., Leme, J. M., Machado, A. F. (2011c). Taphonomic analysis and geometric modeling for the reconstitution of the Ediacaran metazoan Corumbella werneri Hahn et al. 1982 (Tamengo Formation, Corumbá Basin, Brazil). Journal of taphonomy, 9(4), 269-283.

Paim, P. S. G., Leipnitz, I., Da Rosa, A. A. S., Zucatti Da Rosa, A. L. (1997). Preliminary report on the occurrence of Chancelloria sp. in the Itajaí Basin, Southern Brazil. Revista Brasileira de Geociências, 27(3), 303-308,.

Seilacher, A. (1983). Paleozoic sandstones in southern Jordan: Trace fossils, depositional environments and biogeography. In: Abed, A. M.; Khaled, H. M. Geology of Jordan (200-222). Amman: Proceedings of the First Jordanian Geological Conference, 209-222.

Seilacher, A. (1984). Late Precambrian and Early Cambrian Metazoa: Preservational or real extinctions? In: Holland, H. D.; Trendal, A. F. Patterns of Change in Earth Evolution (Dahlem Konferenzen, 159-168). Heidelberg: Springer Verlag, 159-168.

Seilacher, A. (1989). Vendozoa: organismic construction in the Proterozoic biosphere. Lethaia, 22, 229-239.

Seilacher, A. (1992). Vendobionta and Psammocorallia: lost constructions of Precambrian evolution. Journal of the Geological Society, 149, 607-613.

Seilacher, A. (1999). Biomat-related lifestyles in the Precambrian. Palaios, 14, 86-93.

Seilacher, A. (2007). The nature of vendobionts. In: Vickers-Rich, P.; Komarower, P. The Rise and Fall of the Ediacaran Biota. Geological Society of London, special publication, 286, 387-397.

Seilacher, A., Grazhdankin, D., Legouta, A. (2003). Ediacaran biota: the dawn of animal life in the shadow of giant protists. Paleontological Research, 7(1), 43-54.

Seilacher, A., Pflügger, F. (1994). From biomats to benthic agriculture: a biohistoric revolution. In: Krumbein, W. E.; Paterson, D. M.; Stal, L. J. Biostabilization of Sediments (97-105). Oldenburg: Bibliotheks- und Informationssystem der Universität Oldenburg, 97-105. 
Silva, L. C., Armstrong, R., Pimentel, M. M., Scandolara, J., Ramgrab, G., Wildner, W., Angelim, L. A. A., Vasconcelos, A. M., Rizzoto, G., Quadros, M. L. E. S., Sander, A., Zucatti Da Rosa, A. L. (2002). Reavaliação da evolução geológica em terrenos pré-cambrianos brasileiros com base em novos dados U-Pb SHRIMP, Parte III: Províncias Borborema, Mantiqueira Meridional e Rio Negro-Juruena. Revista Brasileira de Geociências, 32(4), 529-544.

Sprigg, R. C. (1947). Early Cambrian (?) jellyfishes from the Flinders Ranges, South Australia. Transactions of the Royal Society of South Australia, 71, 212-223.

Sprigg, R. C. (1949). Early Cambrian "jellyfishes" of Ediacara, South Australia and Mount John, Kimberley District, Western Australia. Transactions of the Royal Society of South Australia, 73, 72-99.

Stanley, S. M. (1973). An ecological theory for sudden origin of multicellular life in the Late Precambrian. Proceedings of the National Academy of Sciences, 70(5), 1486-1489.

Van Iten, H., Leme, J.M., Marques, A. C., Simões, M. G. (2013). Alternative interpretations of some earliest Ediacaran fossils from China. Acta Palaeontologica Polonica, 58(1), 111-113. DOI: 10.4202/app.2011.0096.

Waggoner, B. (2003). The Ediacaran biotas in space and time. Integrative and Comparative Biology, 43, 104-113.

Walde, D. H. G., Leonardos, O. H., Hahn, G., Hahn, R., Pflug, H. (1982). The first Precambrian megafossil from South América, Corumbella werneri. Anais da Academia Brasileira de Ciências, 54(2), 461.

Warren, L. V., Fairchild, T. R., Gaucher, C., Boggiani, P. C., Poiré, D. G., Anelli, L. E., Inchausti, J. C. G. (2011). Corumbella and in situ Cloudina in association with thrombolites in the Ediacaran Itapucumi Group, Paraguay. Terra Nova, 23(6), 382-389. DOI: 10.1111/j.1365-3121.2011.01023.x.

Warren, L. V., Pacheco, M. L. A. F., Fairchild, T. R., Simões, M. G., Riccomini, C., Boggiani, P. C., Cáceres, A. A. (2012). The Dawn of animal skeletogenesis: ultrastructural analysis of Ediacaran metazoan Corumbella werneri. Geology. DOI: 10.1130/G33005.1.
Wood, R. A. (2011). Paleoecology of the earliest skeletal metazoan communities: Implications for early biomineralization. Earth Science Reviews, 106, 184-190. DOI: 10.1016/j.earscirev.2011.01.011.

Xiao, S., Laflamme, M. (2009). On the eve of animal radiation: phylogeny, ecology and evolution of the Ediacara biota. Trends in Ecology and Evolution, 24(1), 31-40. DOI: 10.1016/j.tree.2008.07.015.

Xiao, S., Yuan, X., Steiner, M., Knoll, A. H. (2002). Macroscopic carbonaceous compressions in a terminal Proterozoic shale: a systematic reassessment of the Miaohe biota, South China. Journal of Paleontology, 76, 345-374.

Yi, Q., Van Iten, H., Cox, R. S., Zhu, M-Y., Zhuo, E-J. (1997). A brief account of Emeiconularia trigemme, a new genus and species of protoconulariids. Acta Micropalaeontologica Sinica, 14, 475-488.

Yuan, X., Chen, Z., Xiao, S., Zhou, C., Hua, H. (2011). An early Ediacaran assemblage of macroscopic and morphologically differentiated eukaryotes. Nature, 470, 390-393. DOI: 10.1038/nature09810.

Zaine, M. F. (1991). Analise dos fósseis de parte da Faixa Paraguai (MS, MT) e seu contexto temporal e paleoambiental. 1991. Tese (Doutorado) - São Paulo: Instituto de Geociências - USP.

Zaine, M. F., Fairchild, T. R. (1985). Comparison of Aulophycus lucianoi Beurlen \& Sommer from Ladário (MS) and the genus Cloudina Germs, Ediacaran of Namibia. Anais Academia Brasileira de Ciências, 57,130

Zaine, M. F., Fairchild, T. R. (1987). Novas considerações sobre os fósseis da Formação Tamengo, Grupo Corumbá, SW do Brasil. In: X Congresso Brasileiro de Paleontologia Rio de Janeiro: SBP, 2, 797-806.

Zucatti Da Rosa, A. L. (2005). Evidências de vida no Ediacarano Inferior da Bacia do Itajaí, SC. Dissertação (Mestrado) - São Leopoldo (RS): Centro de Ciências Exatas e Tecnológicas - Universidade do Vale do Rio dos Sinos. 